RESEARCH ETHICS

\title{
Ethical concerns regarding guidelines for the conduct of clinical research on children
}

\author{
S D Edwards, M J McNamee
}

J Med Ethics 2005;31:351-354. doi: 10.1136/ime.2004.009555

In this article we examine ethical aspects of the involvement of children in clinical research, specifically those who are incapable of giving informed consent to participate. The topic is, of course, not a new one in medical ethics but there are some tensions in current guidelines that, in our view, need to be made explicit and which need to be responded to by the relevant official bodies. In particular, we focus on tensions between the World Medical Association Declaration of Helsinki, and the guidance offered by the British Medical Association, the Royal College of Paediatrics and Child Health (formerly the British Paediatric Association), and the Council for International Organizations of Medical Sciences. We conclude with a call for these organisations to make their guidance explicit in relation to the World Medical Association Declaration.

See end of article for authors' affiliations

Correspondence to: S D Edwards, Centre for Philosophy, Humanities and Law in Healthcare, School of Health Science, University of Wales Swansea, Swansea SA2 8PP, UK; s.d.edwards@ swansea.ac.uk

Received 28 May 2004 In revised form 15 July 2004 Accepted for publication 17 July 2004
। n this article we examine ethical aspects of the involvement of children in clinical research, specifically those who are incapable of giving informed consent to participate. Although this is our focus, we recognise of course that many children may be capable of giving informed consent to take part in clinical research-they may be 'Gillick competent'.

Although discussion of the ethical aspects of research on children is not new in medical ethics, $^{23}$ there are some tensions in current guidelines that, in our view, need to be made explicit and which need to be responded to by the relevant official bodies. In particular, we focus on tensions between the World Medical Association (WMA) Declaration of Helsinki and the guidance offered by the British Medical Association (BMA), the Royal College of Paediatrics and Child Health (RCPCH; formerly the British Paediatric Association (BPA)), and the Council for International Organizations of Medical Sciences (CIOMS). We conclude with a call for these organisations to make clear their guidance explicitly in relation to the WMA Declaration.

It should be acknowledged that guidelines, of necessity, express general norms and are open to varying interpretations. Nonetheless, it is reasonable to point to plausible interpretations of such guidelines on which to focus discussion. The following should be understood in the light of our explicit acknowledgement that our interpretations of the guidelines that we discuss are interpretations. Notwithstanding this, the interpretations are supported by the text and are neither extreme nor outlandish.

\section{THE IMPORTANCE OF CLINICAL RESEARCH ON, WITH, AND FOR CHILDREN}

It should be stated at the outset that there are indeed good reasons for conducting clinical research on children. Three of those reasons are now given. First, certain diseases are characteristically childhood diseases and so meaningful research on them needs to be conducted on children. Secondly, there are well known problems in extrapolating pharmacological data from adults to children owing to metabolic differences between children and adults. ${ }^{2}$ Because of such differences the effects of drugs may vary (effects may be dangerously enhanced or paradoxically diminished-differences in pharmacokinetics). Reye's syndrome provides an instructive example. This syndrome can be caused by giving aspirin to children under the age of 12 years. It took some years of clinical experience before anyone realised the connection between aspirin and Reye's syndrome. This is a classic example of a very specific age related metabolic difference-which can have fatal consequences-being undetected because the drug had not been tested in children. In addition, owing to the dearth of research carried out on children, many drugs used in their treatment have not been tested on them by means of clinical trials. ${ }^{23}$ Thirdly, research on children is necessary to determine what is normal development in order to ensure that treatments given are appropriate; ${ }^{4}$ in other words, conditions can be identified as abnormal only when they are seen in relation to what is normal.

Although these are indeed good grounds in favour of conducting research on children, the absence of their consent, in conjunction with their vulnerability, present important countervailing considerations. If research is to be permitted upon non-consenting children it is therefore crucial that there are appropriate guidelines governing the selection of children and the conduct of the research. This is an especially important point in the current climate in which pharmaceutical companies are seeking to develop treatments for childhood diseases such as attention deficit disorder, childhood

Abbreviations: BMA, British Medical Association; BPA,
British Paediatric Association; CIOMS, Council for
International Organizations of Medical Sciences; RCPCH,
Royal College of Paediatrics and Child Health; WMA, Royal College of Paediatrics
World Medical Association 
autism, and more general childhood psychopathologies. Yet current guidelines, we show, generate considerable confusion.

In what follows we shall begin with the position enshrined in the WMA Declaration of Helsinki and show how it is at odds with guidelines offered by the BMA, the RCPCH/BPA, and CIOMS.

\section{THE WMA DECLARATION OF HELSINKI $(2000)^{5}$}

It is fair to observe that this declaration provides the backdrop against which the legitimacy of other guidelines concerning the ethical conduct of research are constrained. This is of course signalled in its title (a product of the World Medical Association). In addition, as would be expected, the $\mathrm{RCPCH} / \mathrm{BPA}$, for example, indicate that their guidelines are so constrained, ${ }^{46}$ so too is the EU clinical trials directive. ${ }^{7}$

The WMA Helsinki Declaration prioritises the welfare of the research participant over the interests of research institutions and society more generally. Thus:

In medical research on human subjects, considerations related to the well-being of the human subject should take precedence over the interests of science and society (clause 5)..$^{5}$

The position expressed in this clause is also endorsed by the RCPCH guidelines, ${ }^{4}$ article $5(\mathrm{~h})$ of the EU clinical trials directive (according to which, "The interests of the patient always prevail over those of science and society" $),{ }^{7}$ and the CIOMS guidelines. ${ }^{8}$

Although not so precise, or as strict, as may be preferred by those who wish absolutely to protect the participant, a plausible interpretation of the clause could run as follows. The wellbeing of the human participant counts for more, morally speaking, than scientific progress-for example, in the form of acquisition of new knowledge; and the wellbeing of the participant counts for more, morally speaking, than the interests of society. Thus, even if the performance of a type of medical research promised vast social benefits, they would not be sufficient to make the conduct of such research morally justified.

It should be stressed that, as with any piece of text, there is scope for differences in the interpretation of this clause. Nonetheless, that just offered seems a fair and natural reading of it.

Suppose one is asked to provide a philosophical defence of clause 5, how could one do this? If one were to articulate a robust moral foundation for the clause, a credible starting point can be found in Kant's "practical imperative". According to this, one must:

Act in such a way that you always treat humanity, whether in your own person or in the person of any other, never simply as a means, but always at the same time as an end.

Invocation of Kant's imperative helps to explain just what would be wrong from the moral point of view with violating the Helsinki clause. If a person is researched upon without their consent, simply to promote the interests of science or society, that person is being used simply as a means, an instrument of external agencies and their ends, in violation of the imperative.

It is worth making two additional points in broad support of the Kantian imperative. The first is that the wrongness of using other human beings simply as a means to one's own (or others') ends is a widely shared aspect of ordinary morality. To be described as a person who uses others for his or her own ends is to be described in terms that are morally critical. A good person would be disturbed to learn that others viewed him or her in such a way. Related terms, similarly, give voice to moral criticism of others in the same way-for example, to describe a person as devious, disrespectful, or manipulative.

The second point in support of the Kantian line is more abstract. This is that it provides a foundation for moral ontology. ${ }^{90}$ Although it is a violation of the imperative to use a human being merely as a means, it is not a violation of it to use a pen merely as a means. The reason is that there is a clear moral difference between human beings on the one hand and pens or other tools on the other. Of course, there are also borderline cases-for example, for some, it is impermissible to use non-human animals merely as means; for others, there is no such moral difficulty in so doing. The difference here stems from disagreement about the boundaries of Kant's imperative. Are non-human animals included, or does it exclusively concern humans (and indeed does it apply to all humans)? Fortunately, the question of whether non-human animals fall within the scope of the imperative can be set aside since our main concern is with children.

Thus far we have reminded readers of a key clause in the WMA Declaration of Helsinki (2000) and also of a moral foundation for it deriving from Kant. Before moving on to assess some current guidelines regarding research on children, a further reminder is required. This concerns the vulnerability of the child in medical research.

\section{THE VULNERABILITY OF CHILD PARTICIPANTS}

It is plausibly held that all research participants are in a position of vulnerability; they are in a situation in which they could suffer harm. ${ }^{11}$ This is the case even if they are capable of consenting to participate in medical research. Typically the relationship between researcher and participant is not an "equal" one. ${ }^{112}{ }^{12}$ The former has qualifications and high social status; the patient may think that he or she lacks these attributes.

In groups such as children this state of vulnerability seems even more acute. ${ }^{46}$ If they are ill and in hospital, they are in strange surroundings. They may be frightened. They are aware that they are ill and may feel obliged to help those caring for them. As a result they may feel under particular pressure to agree to any request for help by anyone perceived as being involved in their medical care. They may believe their care could be jeopardised by refusing a request to take part in medical research. This all applies to their parents too of course. They may feel they should agree to their child taking part in research so that he or she is seen as cooperative, as a good patient.

This now takes us on to the more critical part of our discussion. As mentioned above, we will draw attention to some difficulties with guidelines presented by the BMA (in the recent publication Medical ethics today; the BMA's handbook of ethics and $\left.l a w^{13}\right)$, and then proceed to do the same with guidelines provided by the RCPCH/BPA and CIOMS respectively.

\section{CONCERNS REGARDING BMA GUIDELINES ${ }^{13}$}

As mentioned in the introduction, the focus of this article is on clinical research on children who are incapable of giving informed consent to participate in such research. As the above named BMA guidelines indicate, if children are not competent to give informed consent to take part in clinical research the consent of their parents or guardians is required-that is, so called "proxy consent" (p 511). ${ }^{13}$

However, the BMA discussion continues, there are, of course, limits to parents' (proxy) consent: (a) "People with parental responsibility ... cannot agree to any intervention 
contrary to the child's best interests" (p 511) ${ }^{13}$; and (b) the child's consent or assent to the involvement is also required. If the child shows active unwillingness to take part, this should be respected. If parents disagree, the BMA advises "great caution" (p 512).13

It may be objected that the restrictions just described in this most recent BMA book are not restrictive enough, but are excessively permissive. Note that the intervention must not be "contrary to the child's best interests" (p 511). ${ }^{13}$ However, it could reasonably be claimed that any morally defensible involvement of a child in clinical research must in fact be in the child's best interests, not merely not contrary to the child's best interests.

Such a claim receives support from our Kantian injunction. Suppose a research project involves a child. Involvement in the research is not in his or her best interests, but neither is it contrary to the child's best interests. It may be said that such a child is in fact being used merely as a means. The child has not consented (let us agree), and the research is not being performed for the benefit of the child. Surely, such a child is being used simply as a means. It may be true that the use serves a morally good end, but, as we saw above, being beneficial to third parties may be a necessary condition of defensible research, but it is not a sufficient one.

The question of whether guidelines relating to the conduct of clinical research on children are overly permissive is one we will raise again during consideration of those provided by the RCPCH/BPA and CIOMS.

\section{RCPCH/BPA GUIDELINES 46}

In their ethical guidelines for conducting medical research on children, the RCPCH states: "A research procedure which is not intended directly to benefit the child subject is not necessarily either unethical or illegal" (p 177). ${ }^{4}$ Examples given are "observing and measuring normal development, assessing diagnostic methods, the use of 'healthy volunteers' and of placebos in controlled trials" (p 178). ${ }^{4}$

Readers will recall that the RCPCH distinguishes three categories of risk: minimal, low, and high. Minimal risk includes "...using blood from a sample that has been taken as part of treatment" (p 179). ${ }^{4}$ Low risk includes "procedures that cause brief pain or tenderness, and small bruises or scars [for example] ... injections and venepuncture" (p 179). "High risk procedures such as lung or liver biopsy ... are not justified for research purposes alone ..." (p 179). ${ }^{4}$

As originally formulated, before an amendment that we will discuss very shortly, the RCPCH/BPA guidelines included the following clause: "It would be unethical to submit child subjects to more than minimal risk when the procedure offers no benefit to them, or only a slight or very uncertain one $^{\prime \prime}$ ( $\mathrm{p}$ 9). ${ }^{6}$ Thus, according to this original version of the guidelines, venepuncture would not be ethically defensible if the research is intended to benefit future child patients, and will not benefit the individual child research participant. This version certainly respects the Kantian imperative, and unequivocally respects clause 5 of the WMA Helsinki Declaration, but apparently the original formulation was considered excessively restrictive and was subsequently revised as follows:

We believe that research in which children are submitted to more than minimal risk with only slight, uncertain or no benefit to themselves deserves serious ethical consideration ( $p$ 179, reference 4; and $p 11$, reference 6).

Thus research involving-for example, venepuncture, is now thought permissible, having previously been deemed unethical. The revised version is surely vulnerable to the charge of being excessively permissive. It now omits to forbid research in which child participants are used merely as means for the benefit of future children. Thus it seems to transgress the Kantian imperative. It also seems to violate clause 5 of the WMA Helsinki Declaration; as already noted, this forbids research that places the interests of other parties over the wellbeing of the research participant. Assuming (quite reasonably) that having unnecessary pain inflicted upon one runs counter to one's wellbeing, it follows that the revised RCPCH/BPA guideline conflicts with the WMA Declaration of Helsinki.

It is also pertinent to ask whether this $\mathrm{RCPCH} / \mathrm{BPA}$ guideline is at odds with the BMA advice quoted above. According to this, parents cannot consent to research that is contrary to their child's best interests. It is hard to see how it can be in a child's best interests to be a research participant undergoing venepuncture for the benefit of future children; in fact it seems plausible to regard it to be contrary to a child's best interests to undergo such non-therapeutic procedures.

In defence of the RCPCH/BPA guidelines it may be pointed out that it is a feature of them that it permits children themselves to determine whether an intervention presents a low or a minimal risk. ${ }^{4}$ However, this can apply only when children are capable of making such a determination. Very young children (for example, those who are less than 1 year old) will not be so capable, and it seems reasonable to point out that even older children may not be able to make such an assessment until after the intervention has been carried out (for example, if they have not previously experienced the procedure). The concerns raised here against the RCPCH guidelines therefore seem to stand, and we turn now to the CIOMS guidelines.

\section{CIOMS GUIDELINES ${ }^{8}$}

CIOMS guideline 9 ("Special limitations on risk when research involves individuals who are not capable of giving informed consent") focuses on risk to participants who are unable to consent, including children:

When there is ethical and scientific justification to conduct research with individuals incapable of giving informed consent, the risk from research interventions that do not hold out the prospect of direct benefit for the individual subject should be no more likely and not greater than the risk attached to routine medical or psychological examination of such persons. Slight or minor increases above such risk may be permitted when there is an overriding scientific or medical rationale for such increases and when an ethical review committee has approved them $(p 30) .{ }^{8}$

Guideline 9 holds explicitly that research that involves a certain level of risk is justified even when the participant will not benefit directly from the research. Two levels of risk are specified: (a) a "low risk standard"; and (b) a standard slightly above this.

The low risk standard indicates that research on noncompetent children can be justified provided the risk of harm to participants is not greater than the risk of harm incurred during-for example, "routine medical ... examination" (p 30). ${ }^{8}$ Of course, "venepuncture" may be part of such an examination.

Hence, this guideline seems to endorse research on incompetent children that: (a) does not directly benefit the child; and (b) may include risk of harm ("low risk"). This guideline may lead to the violation of clause 5 of the WMA Declaration of Helsinki. Unless the child has an untreatable condition, it is not clear how it can be in the child's interest to permit himself or herself to be used merely as a means for the 
benefit of future patients. Note too that the CIOMS clause permits such research even if the risks of harm to the nonconsenting participant are in fact greater than a low risk-for example, if they involve "slight or minor increases above [low] risk" (p 30). ${ }^{8}$

\section{THERAPEUTIC AND NON-THERAPEUTIC RESEARCH}

With the exception of the most recent WMA Declaration of Helsinki, the guidelines discussed above each seem to presuppose the possibility of drawing a robust distinction between therapeutic and non-therapeutic research. Thus, for example, recall the RCPCH statement quoted above: "A research procedure which is not intended directly to benefit the child subject is not necessarily ... unethical" ${ }^{4}$. The clear implication here is that some research can be of direct benefit to child participants, but such a distinction has been subject to criticism. ${ }^{14}{ }^{15}$ Critics point out that the research context is one in which the primary aim is extension of knowledge, not the wellbeing of research participants (although of course this should not be neglected). Thus, contrary to the guidelines discussed above, it is far from clear that a robust distinction between therapeutic and non-therapeutic research can be articulated.

The implications of this for our discussion are as follows. Suppose it is allowed that there is a distinction between therapeutic and non-therapeutic research. Two positions concerning the ethics of research on non-consenting children are coherent ones. The first permits such research providing it is therapeutic in nature (providing the participant benefits directly). The second forbids it on grounds that there is no direct benefit to the participant. If, however, it is accepted that the distinction between therapeutic and non-therapeutic research is spurious, then the two positions are no longer available. If one shows non-therapeutic research on children who are incapable of giving consent to be morally objectionable, one thereby shows all such research on non-consenting children to be morally objectionable. Our discussion has refrained from advancing this radical claim. Instead, we have queried the defensibility of research on non-consenting children that is of no benefit to them (is non-therapeutic), and which involves the experience of some discomfort or pain on their part. As shown, current guidelines seem to permit the possibility of such research. We have argued that such a permissive stance is not consistent with clause 5 of the WMA Declaration of Helsinki.

\section{CONCLUSION}

In the light of these observations concerning guidelines offered by the BMA, the RCPCH/BPA and the CIOMS, we conclude that, in comparison with the standards set out in clause 5 of the WMA Declaration of Helsinki, they are excessively permissive. The question then arises of whether they are in fact overly permissive. That is to say, should the restrictions on ethically defensible research stated in clause 5 of the Declaration be revised "downwards" so to speak, to permit more kinds of research? We do not have space to discuss this here, but, given the Kantian imperative examined above, it would prove difficult to support lowering the standard of defensible medical research to that below the standard specified in clause 5 .

Given the conflict between the BMA, RCPCH/BPA, and CIOMS guidelines on the one hand and the Helsinki Declaration on the other, some statement from these organisations is urgently needed. As mentioned above, it is commonly assumed that the WMA Declaration provides a background that all ethically defensible guidelines concerning research on humans must not transgress. Yet, as we have shown, at least three current sets of guidelines seem to permit transgression of one of its key clauses.

\section{ACKNOWLEDGEMENTS}

The authors are grateful to Paul Wainwright for comments on earlier drafts of this paper, and also to two referees of this journal for helpful criticism.

\section{Authors' affiliations}

S D Edwards, M J McNamee, Centre for Philosophy, Humanities and Law in Healthcare, School of Health Science, University of Wales

Swansea, Swansea SA2 8PP, UK

\section{REFERENCES}

1 Mason JK, McCall Smith RA. Law and medical ethics, 4th ed. London: Butterworths, 1994:94

2 Nicholson R, ed. Medical research with children. Oxford: Oxford University Press, 1986.

3 Kopelman L. Children as research subjects: a dilemma. J Med Philos 2000;25:745-64.

4 Royal College of Paediatrics and Child Health. Guidelines for the ethical conduct of medical research involving children. Arch Dis Child 2000:82:177-82.

5 World Medical Association. Declaration of Helsinki. Ethical principles for medical research involving human subjects. Ferney-Voltaire: WMA, 2000.

6 British Paediatric Association. Guidelines for the ethical conduct of medical research involving children. London: BPA, 1992.

7 European Union. European Union clinical trials directive. Luxembourg: EU, 2001.

8 Council for International Organizations of Medical Sciences. International ethical guidelines for biomedical research involving human subjects. Geneva: CIOMS, 2002.

9 Kant I. Groundwork of the metaphysic of morals. (First published 1785.) In: Paton $\mathrm{H}$, ed. The moral law. London: Hutchinson, 1948:91.

10 Ross P. De-privatizing morality. Aldershot: Ashgate, 1994.

11 Evans M, Evans D. A decent proposal. Chichester: Wiley, 1996

12 Alderson P. Children's consent to surgery. Buckingham: Open University Press, 1993.

13 British Medical Association. Medical ethics today; the BMA's handbook of ethics and law, 2nd ed. London: BMA, 2004.

14 Spriggs M. Canaries in the mines: children, risk, non-therapeutic research and justice. J Med Ethics 2004;30:176-81.

15 Edwards SD. An argument against research on people with intellectual disabilities. Medicine, Health Care and Philosophy 2000;3:69-73. 